\title{
Enhancement of proton conductivity of sulfonated polystyrene membrane prepared by plasma polymerization process
}

\author{
BHABESH KUMAR NATH, AZIZ KHAN, JOYANTI CHUTIA*, ARUP RATAN PAL, \\ HEREMBA BAILUNG, NEELOTPAL SEN SARMA, DEVASISH CHOWDHURY \\ and NIRAB CHANDRA ADHIKARY
}

Physical Science Division, Institute of Advanced Study in Science and Technology, Paschim Boragaon, Guwahati 781 035, India

MS received 5 July 2013; revised 6 December 2013

\begin{abstract}
This work reports the achievement of higher proton conductivity of polystyrene based proton exchange membrane synthesized in a continuous RF plasma polymerization process using two precursors, styrene $\left(\mathrm{C}_{8} \mathrm{H}_{8}\right)$ and trifluoromethane sulfonic acid $\left(\mathrm{CF}_{3} \mathrm{SO}_{3} \mathrm{H}\right)$. The chemical composition of the developed membranes is investigated using Fourier transform infrared spectroscopy and energy dispersive spectroscopy. Scanning electron microscopy has been used for the study of surface morphology and thickness measurement of the membrane. The membranes deposited in the power range from 0.114 to $0.318 \mathrm{Wcm}^{-2}$ exhibit a lot of variation in the properties like proton transport, water uptake, sulfonation rate, ion exchange capacity and thermal behaviour. The proton conductivity of the membranes is achieved up to $0.6 \mathrm{Scm}^{-1}$, measured with the help of potentiostat/galvanostat. The thermogravimetric study of the plasma polymerized membrane shows the thermal stability up to $140{ }^{\circ} \mathrm{C}$ temperature.
\end{abstract}

Keywords. Plasma polymerization process; ion exchange capacity; proton conductivity; thermal stability.

\section{Introduction}

The present day research on green energy has been highly focused on the development of proton exchange membrane fuel cells as a new promising technology of power generation in increased environmental concern. Due to high efficiency and low environmental pollution, proton exchange membrane fuel cell (PEMFC) is preferred as a clean energy source for transportable, stationary and portable power applications (Xing et al 2004; Yeom et al 2005; Morse 2007; Psark et al 2007; Wan et al 2007). The PEMFC consists of two electrodes separated by a polymer membrane which is the heart component of the fuel cell. The function of the polymer membrane is primarily to exchange protons formed at the anode side by hydrogen oxidation reaction (HOR) to the cathode side where they take part in oxygen reduction reaction (ORR). The required physical properties of the polymer electrolytic membrane include good functional properties like proton conductivity, water transport property, high gas barrier properties, higher thermal and chemical stability and durability. The polymeric proton exchange membrane (PEM) mainly consists of two different ingredients, one of which fabricates the backbone structure of the membrane while the other one yields the functional property to the membrane. To exchange the proton through the polymeric matrixes,

\footnotetext{
*Author for correspondence (jchutiaiasst@gmail.com)
}

electronegative groups like $-\mathrm{SO}_{3}^{-},-\mathrm{PO}_{3}^{2-},-\mathrm{COO}^{-}$etc are incorporated into the polymer back bone (Peighambardoust et al 2010). Over the last few decades, lots of work have been done to develop such type of membranes which meet all the above requirements. Chemically prepared nafion membranes with fluoro-carbon back bone developed by Du-Pont are currently the most used membranes which have the highest proton conductivity of about $0 \cdot 155 \mathrm{Scm}^{-1}$ at room temperature (Jiang et al 2011). But, it has the disadvantage of low proton conductivity at operating temperature greater than $100{ }^{\circ} \mathrm{C}$ due to evaporation of water molecules and low mechanical strength due to lack of inter-molecular crosslinking among the polymer backbone chains. To overcome these drawbacks of proton exchange membrane prepared by chemical process, people have been trying to develop proton conducting membrane using plasma polymerization process. Plasma polymerization is one of the convenient powerful processes of polymerization by which thin, uniform, highly cross-linked and pinhole free polymer films can be developed (Bae et al 2005). The membrane prepared by plasma process achieves higher thermal and mechanical strength better than chemically polymerized membranes (Yasuda et al 1976; Yasuda 1981). Research has been continuously growing in the plasma polymerization process to develop a membrane with superior properties compared to membranes prepared by other processes. Although this process is quite efficient for material synthesis, it has some disadvantages as the continuous degradation of monomer takes place during 
polymerization which makes it difficult to incorporate some specific groups into the polymer backbone (Poll et al 1976; Yasuda et al 1976; Yasuda 1981). This technique prefers a mixture of monomers to polymerize under the plasma environment. Several research groups have prepared this kind of plasma polymerized membranes by using a mixture of two precursors in order to attain the specific properties of each of them (Inagaki et al 1989; Brumlik et al 1994; Yasuda et al 1994a, b; Roualdes et al 2007; Ennajdaoui et al 2008; Jiang et al 2010a, b, 2011). Generally, in fabrication of polymer electrolyte membrane with plasma polymerization process, monomers such as vinyl benzene, fluorocarbon, etc. are used to develop the backbone structure of the polymer and some other chemicals or monomers having specified functional groups are used to attribute the functional property. The best results have been observed in combination of styrene and trifluoromethane sulfonic acid (TMSA) which gives the good proton conductivity achieved so far 0.181 $\mathrm{Scm}^{-1}$ almost comparable to the nafion membrane (Jiang et al 2011). In this study, attempt is made to enhance the proton conductivity of plasma polymerized membrane better than that of commercially available nafion membrane. Plasma polymerized sulfonated polystyrene membranes are prepared in continuous RF glow discharge process with horizontal and parallel electrode configuration and vertical polymer deposition on the cathode under different plasma conditions. The prepared membranes are characterized using Fourier transform infrared (FTIR) spectroscopy, scanning electron microscopy (SEM), energy dispersive spectroscopy (EDS) and thermo-gravimetric analysis (TGA).

\section{Experimental}

\subsection{Preparation of membrane}

The deposition of sulfonated polystyrene membrane was carried out in a plasma polymerization reactor under RF glow discharge. The mixture of styrene and TMSA supplied by Merck Schuchardt OHG, Germany, was polymerized between two capacitively coupled inner disk electrodes placed horizontally and parallelly inside the plasma reactor as shown in figure 1 .

The reactor consists of a cylindrical stainless steel plasma chamber of $40 \mathrm{~cm}$ in diameter and $45 \mathrm{~cm}$ in height. The electrode of $10 \mathrm{~cm}$ diameter used in this experiment was connected to $13.56 \mathrm{MHz}$ RF source (Seren, USA). A vacuum pumping system was connected to the bottom part of the chamber to evacuate the chamber up to the order of $10^{-5}$ mbar pressure. A capacitance manometer (Baratron, MKS Instruments, USA, $10^{-4}-1$ mbar) fitted in the chamber was used to monitor the chamber pressure during experiment. To introduce the styrene monomer into the chamber, a shower plate was connected with inlet of the monomer bath. The shower plate has 60 holes each of $0.5 \mathrm{~mm}$ diameters to ensure a uniform distribution of styrene monomer in the plasma region and it was placed $5 \mathrm{~cm}$ above the working electrode.
The styrene monomer bath was kept outside the chamber and immersed in a temperature bath and TMSA monomer kept in another bath was introduced through a ring shower placed at the edge of the live electrode to ensure uniform distribution of monomer vapour. Both styrene and TMSA monomers were kept at constant temperature of $28^{\circ} \mathrm{C}$. To carry out the plasma polymerization of styrene/TMSA mixture, firstly the chamber pressure was reduced to the order of $10^{-5}$ mbar with the help of a diffusion pump backed by a rotary pump. On achieving the required base pressure, styrene monomer vapour was released into the chamber and then diffusion pump was closed allowing only the rotary pump to run. Then the discharge was initiated on styrene vapour at chamber pressure 0.22 mbar. After initiating the discharge, TMSA vapour was also released into the chamber. During the whole period of deposition, the overall chamber pressure was maintained at 0.16 mbar by controlling the amount of TMSA at 10:1 partial pressure ratio of styrene and TMSA. It was observed that when TMSA had been introduced into the chamber, the initial pressure started to decrease by the reaction between styrene and TMSA vapour inside the chamber. So controlling the amount of TMSA, total working pressure was maintained at $0.16 \mathrm{mbar}$. The different operating conditions for the preparation of membrane are shown in table 1 . The membranes, synthesized at different power density are named as PP-SPSM1 synthesized at $0.114 \mathrm{Wcm}^{-2}$, PP-SPSM2 at $0.153 \mathrm{Wcm}^{-2}$, PP-SPSM3 at $0.191 \mathrm{Wcm}^{-2}$, PP-SPSM4 at $0.254 \mathrm{Wcm}^{-2}$ and PP-SPSM5 at $0.318 \mathrm{Wcm}^{-2}$ power density. During the whole experiment, the membranes were developed in the discharge power density range from 0.114 to $0.318 \mathrm{Wcm}^{-2}$ at constant working pressure and a deposition time of $25 \mathrm{~min}$. The plasma polymerized membranes were deposited on the silicon wafer substrate placed on the live electrode to investigate the structural characterizations and on Aluminum thin foil to measure the proton conductivity of the membrane. During polymerization, the substrate was maintained at a temperature of $40{ }^{\circ} \mathrm{C}$ using a controlled amount of circulated cold water.

\subsection{Thickness measurement and surface morphology}

The thickness of the prepared membranes was measured using scanning electron microscope (SIGMA/VP FESEM, ZEISS). To measure the thickness of the membrane, firstly the membrane deposited on the silicon wafer was broken smoothly and then cross sectional micrograph of the membrane was evaluated from which the membrane thickness was measured. Surface morphology of the membrane was investigated from the surface micrographs of the membranes using SEM.

\subsection{Structural characterization of the membrane}

Structural composition of the prepared membranes was investigated using FTIR and energy dispersive X-ray spectrometric 


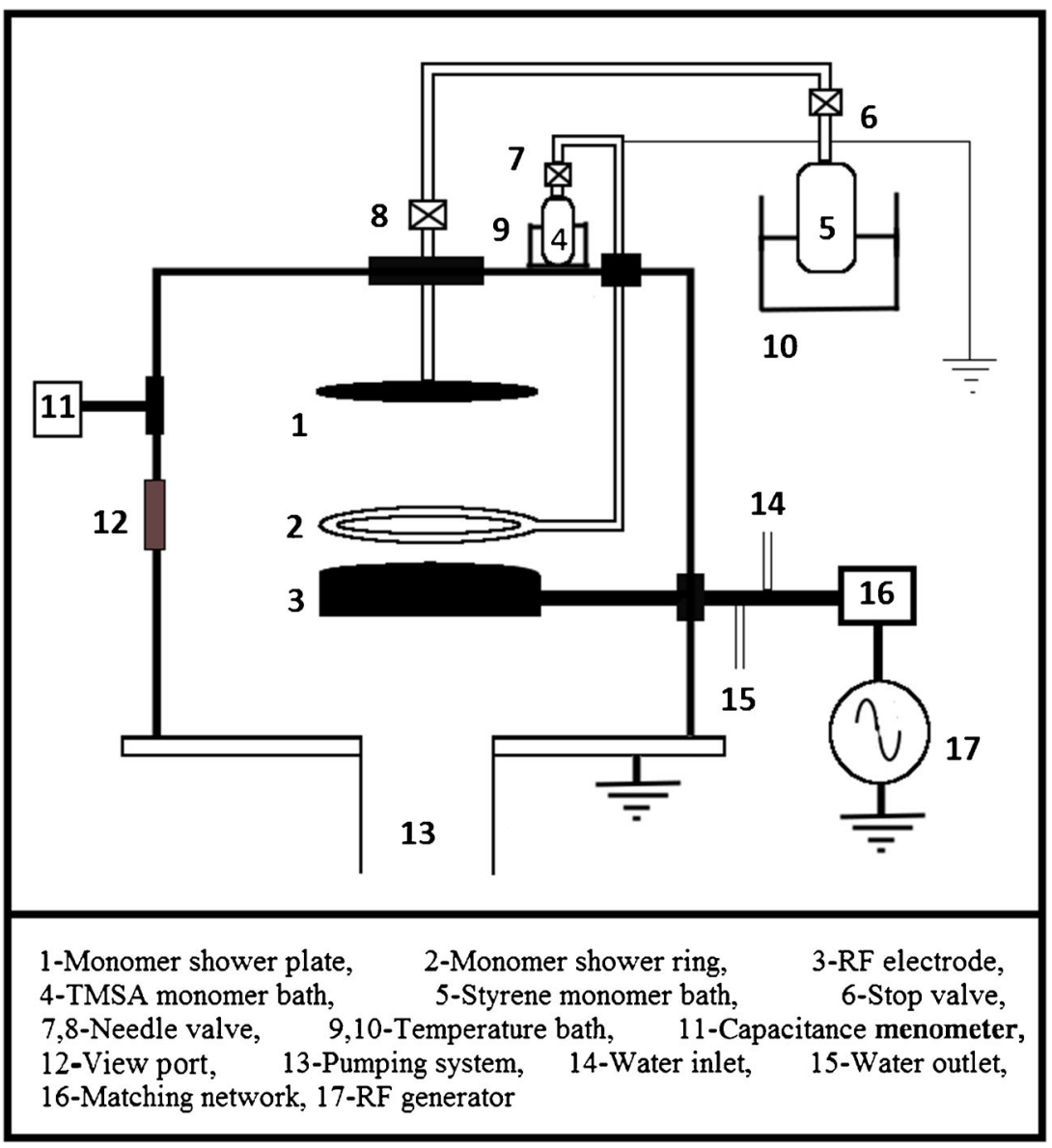

Figure 1. Schematic diagram of RF plasma polymerization system.

Table 1. Operating conditions for plasma polymerization.

\begin{tabular}{lccccc}
\hline Membrane & $\begin{array}{c}\text { Power density } \\
\left(\mathrm{Wcm}^{-2}\right)\end{array}$ & $\begin{array}{c}\text { Initial self } \\
\text { bias (Volt) }\end{array}$ & $\begin{array}{c}\text { Working pressure } \\
(\mathrm{mbar})\end{array}$ & $\begin{array}{c}\text { Partial pressure } \\
\text { ratio (Styrene:TMSA })\end{array}$ & $\begin{array}{c}\text { Deposition time } \\
(\mathrm{min})\end{array}$ \\
\hline PP-SPSM1 & $0 \cdot 114$ & -5 & & & \\
PP-SPSM2 & $0 \cdot 153$ & -6 & & $10: 1$ & \\
PP-SPSM3 & $0 \cdot 191$ & -8 & $0 \cdot 160$ & \\
PP-SPSM4 & $0 \cdot 254$ & -10 & & & \\
PP-SPSM5 & 0.318 & -12 & & & \\
\hline
\end{tabular}

(EDS) analysis. The IR spectra was recorded in FTIR spectrometer (Vector 22, Bruker, Germany) in the range of 400$4000 \mathrm{~cm}^{-1}$ of resolution $4 \mathrm{~cm}^{-1}$ with $32 \mathrm{~s}$ scan rate on each sample in transmitting mode. And energy dispersive $\mathrm{X}$-ray spectrometry was performed using scanning electron microscope (SEM).

From the FTIR spectra, it is possible to estimate the sulfonation rate of the synthesized membrane using the following formula (Ennajdaoui et al 2008, 2010):

$$
\text { Sulfonation rate }(S)=\frac{A_{1027}}{A_{699}+A_{1027}} \times 100 \% \text {, }
$$

where $A_{1027}$ is the peak area at $1027 \mathrm{~cm}^{-1}$ representing the attachment of $-\mathrm{SO}_{3} \mathrm{H}$ groups in the polymer backbone and $A_{699}$ the peak area at $699 \mathrm{~cm}^{-1}$ representing the mono substituted aromatic ring in the polymer matrixes.

\subsection{Water uptake measurement}

To determine the water uptake of the prepared membranes, firstly the membranes were allowed to soak in distilled water for $24 \mathrm{~h}$ to wet completely and then they were removed and wiped with blotting paper to remove the excess water on the surface. The mass of the wet membrane was measured 
by using micro balance (Shimadzu, AUW220D), and then the membrane was vacuum dried for $24 \mathrm{~h}$ at $80{ }^{\circ} \mathrm{C}$ temperature to measure the mass of the dry membrane. The water uptake of the membrane was calculated using the following equation:

$$
\text { Water uptake }=\frac{W_{\mathrm{w}}-W_{\mathrm{d}}}{W_{\mathrm{d}}} \times 100 \%,
$$

where $W_{\mathrm{w}}$ is the mass of the wet membrane and $W_{\mathrm{d}}$ the mass of the dry membrane.

\subsection{Molecular weight measurement}

A three styragel HR2 column gel permeation chromatography (GPC) system (Waters, USA) was employed to study the distribution of molecular weight of prepared sulfonated polystyrene membrane. To perform this experiment, $0.25 \%$ concentrated $50 \mu \mathrm{l}$ tetrahydrofuran (THF) solution of the membrane was injected into the GPC column using a software controlled Waters 7725 i Rheodyne syringe. During the experiment, the flow rate of the THF throughout the column was maintained at $1 \mathrm{mlmin}^{-1}$ and the measured molecular weight of the membranes was calibrated with the standard molecular weights provided in the GPC system.

\subsection{Ion exchange capacity}

The IEC values of the membranes were determined by classical titration method. First, the membrane was soaked in $50 \mathrm{ml} 1.0 \mathrm{M}$ solution of $\mathrm{NaCl}$ for $24 \mathrm{~h}$ to exchange the proton with $\mathrm{Na}^{+}$. Then the acidic $\mathrm{NaCl}$ solution was titrated with $0.01 \mathrm{M} \mathrm{NaOH}$ solution using phenolphthalein as an indicator. The titrated IEC was calculated using the following formula:

$$
\mathrm{IEC}=\frac{C_{\mathrm{NaOH}} \times V_{\mathrm{NaOH}}}{M_{\mathrm{d}}} \times 100 \%,
$$

where $C_{\mathrm{NaOH}}$ and $V_{\mathrm{NaOH}}$ are the concentration and the consumed volume of $\mathrm{NaOH}$ solution respectively. $M_{\mathrm{d}}$ the mass of the dry membrane.

\subsection{Proton conductivity measurements}

The proton conductivity of the membrane was determined with the help of electrochemical impedance spectroscopy using a potentiostat/galvanostat (Gamry Reference 3000) over a frequency range of $10 \mathrm{mHz}-1 \mathrm{MHz}$. To measure the impedance of the plasma polymerized membrane, a para cell device was used which has three kinds of electrodes, mainly the working, counter and the reference electrodes connected to the potentiostat/galvanostat. After equilibrating the membrane in $1 \mathrm{~N} \mathrm{H}_{2} \mathrm{SO}_{4}$ for $24 \mathrm{~h}$ at room temperature, the impedance spectra were recorded and the high frequency intercept on the real axis of the Nyquist plot was evaluated to measure the impedance of the membrane. Then the proton conductivity of the membrane was calculated directly using the following equation (Mahdjoub et al 2005):

$$
\text { Proton conductivity }(\sigma)=\frac{t}{R \times A},
$$

where $t$ is the thickness of the membrane, $R$ the impedance of the membrane and $A=2.65 \mathrm{~cm}^{2}$ the area of the membrane exposed to the $\mathrm{H}_{2} \mathrm{SO}_{4}$ solution.

\subsection{Thermal stability analysis}

TGA was used to study the thermal behaviour of the plasma polymerized membranes and it was performed by a thermogravimetric analyzer (Perkin Elmer TGA 4000). Sample of 5 to $10 \mathrm{mg}$ was heated in the temperature range $35-900{ }^{\circ} \mathrm{C}$ with the heating rate of $10{ }^{\circ} \mathrm{C} \mathrm{min}-1$ under a nitrogen environment and the weight loss of the synthesized materials at different temperatures was observed.

\section{Results and discussion}

\subsection{FTIR analysis for structural characterization}

The chemical structure and bonding related to different groups of the plasma polymerized membranes were investigated from the FTIR spectra. In figure 2, FTIR spectra of all membranes synthesized at different power density are represented. Assigned peaks representing various chemical bonding present in the synthesized plasma polymer are tabulated as shown in table 2 which reveals the existence of different chemical moieties mainly the sulfonated, fluorinated and the carbonated groups from the styrene and $\mathrm{CF}_{3} \mathrm{SO}_{3} \mathrm{H}$. In the FTIR spectra, it is seen that there is a broad band absorption peak near at $1650 \mathrm{~cm}^{-1}$ for all kinds of membranes which correspond to the $\mathrm{C}=\mathrm{C}$ stretch vibration in the vinyl

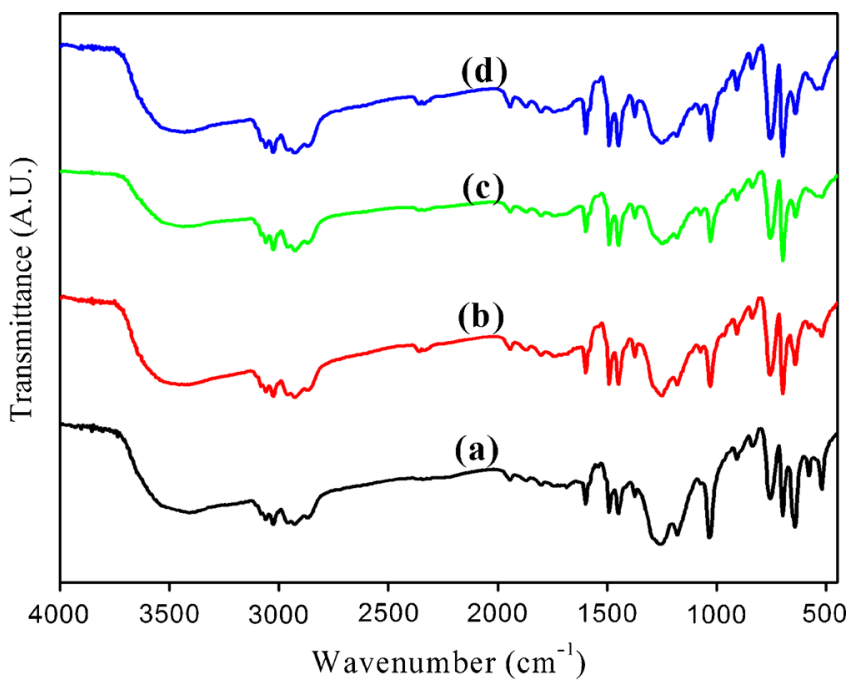

Figure 2. FTIR spectra of the plasma polymerized membranes: (a) PP-SPSM4, (b) PP-SPSM3, (c) PP-SPSM2 and (d) PP-SPSM1. 
Table 2. Assignment of peaks observed in the synthesized plasma polymerized membrane.

\begin{tabular}{|c|c|}
\hline Wave number $\left(\mathrm{cm}^{-1}\right)$ & $\begin{array}{l}\text { Representation of chemical bonding } \\
\text { with chemical groups }\end{array}$ \\
\hline 699 & $\mathrm{C}-\mathrm{H}$ out of plane bending vibrations in mono substituted benzene ring \\
\hline 754 & $\mathrm{C}-\mathrm{H}$ out of plane bending vibrations of five $\mathrm{C}-\mathrm{H}$ bond in aromatic ring \\
\hline 836 & Out of plane bending vibrations of $\mathrm{C}-\mathrm{H}$ for 1,4 para di-substituted in benzene ring \\
\hline 907 & $\mathrm{~S}-\mathrm{O}$ stretching vibrations of $-\mathrm{SO}_{3} \mathrm{H}$ \\
\hline 1027 & $\mathrm{~S}=\mathrm{O}$ symmetric stretching vibrations \\
\hline 1074 & $\mathrm{~S}=\mathrm{O}$ asymmetric stretching vibrations \\
\hline 1180 & Symmetric stretching vibrations of the two $\mathrm{S}=\mathrm{O}$ of $-\mathrm{SO}_{3} \mathrm{H}$ \\
\hline 1260 & $\mathrm{C}-\mathrm{F}$ vibrations \\
\hline 1450 and 1372 & $\mathrm{C}-\mathrm{H}$ bending vibration in $-\mathrm{CH}_{2}$ groups \\
\hline 1492 and 1600 & Aromatic $\mathrm{C}=\mathrm{C}$ stretching \\
\hline 1582 & Non-assigned \\
\hline 2865 & Aliphatic $\mathrm{C}-\mathrm{H}$ symmetric stretching vibrations in $-\mathrm{CH}_{3}$ group \\
\hline 2927 & Aliphatic $\mathrm{C}-\mathrm{H}$ asymmetric stretching vibrations in $-\mathrm{CH}_{2}$ group \\
\hline 3060 and 3080 & Aromatic $\mathrm{C}-\mathrm{H}$ stretching vibrations \\
\hline $1100-1400$ (broad band) & $\begin{array}{l}\text { Asymmetric } \mathrm{CF}_{2} \text { stretching, Symmetric } \mathrm{S}=\mathrm{O} \text { stretching of }-\mathrm{SO}_{3} \mathrm{H} \text { and symmetric } \\
\text { and } \mathrm{S}=\mathrm{O} \text { stretching }\end{array}$ \\
\hline $1667-2000$ (broad band) & Mono and para substitution of benzene ring \\
\hline $3100-3800$ & $\mathrm{O}-\mathrm{H}$ stretching vibrations \\
\hline
\end{tabular}

group of styrene molecule (Pavia et al 2001). So, it may be concluded that the mixture of styrene and $\mathrm{CF}_{3} \mathrm{SO}_{3} \mathrm{H}$ is well copolymerized throughout the plasma phase and constitutes the network of the polymer matrixes. The above band also indicates the bending mode vibration of $\mathrm{O}-\mathrm{H}$ which is much more pronounced in case of plasma polymerized materials than chemically synthesized polymer (Wirguin 1979; Rieke and Vanderborgh 1987; Gruger et al 2001). So, the plasma polymerized materials can be hydrated more easily than the conventional sulfonated polystyrene membrane prepared by chemical process (Blanchard and Nuzzo 2000). The absorption band $1100-1400 \mathrm{~cm}^{-1}$ present in the FTIR spectra reveals the existence of the $-\mathrm{CF}_{2}$ and $-\mathrm{SO}_{3} \mathrm{H}$ groups in the polymer. But it is complicated to distinguish between $-\mathrm{CF}_{2}$ and $-\mathrm{SO}_{3} \mathrm{H}$ due to presence of overlapping contributions relative to each other (Retzko et al 2001). The presence of the absorption peaks at 1027 and $1074 \mathrm{~cm}^{-1}$, corresponding to the $\mathrm{S}=\mathrm{O}$ symmetric and asymmetric stretching vibrations respectively, represents the existence of the $\mathrm{SO}_{3} \mathrm{H}$ groups in the polymer matrixes (Ennajdaoui et al 2010). The same absorption is seen at $1030 \mathrm{~cm}^{-1}$ in the sulfonated polystyrene polymer developed earlier (Rieke and Vanderborgh 1987; Inagaki et al 1989; Mahdjoub et al 2005; Ennajdaoui et al 2008, 2010; Jiang et al 2010a, b). But in our case, this is observed at $1027 \mathrm{~cm}^{-1}$ in the membrane deposited up to power density $0.254 \mathrm{Wcm}^{-2}$ which is similar to chemically prepared sulfonated polysulfone, sulfonated poly(etherether)ketone (Baradie et al 1998; Zhong et al 2006).

The absorption peaks observed at $1180 \mathrm{~cm}^{-1}$, corresponding to symmetric vibration of two $\mathrm{S}=\mathrm{O}$ bonds in $\mathrm{SO}_{3} \mathrm{H}$ groups and $907 \mathrm{~cm}^{-1}$ corresponding to $\mathrm{S}-\mathrm{OH}$ stretching vibration respectively, also signify the presence of $\mathrm{SO}_{3} \mathrm{H}$ groups in the synthesized polymer. The retention of aromatic structure of the polymer is revealed by the peaks $3080 \mathrm{~cm}^{-1}$ and $3060 \mathrm{~cm}^{-1}$ corresponding to the aromatic $\mathrm{C}-\mathrm{H}$ stretching vibration and the peaks 1492 and $1600 \mathrm{~cm}^{-1}$ corresponding to the aromatic $\mathrm{C}=\mathrm{C}$ stretching vibration (Mahdjoub et al 2005). The spectra exhibiting the peaks at 2865, 2927 and $2960 \mathrm{~cm}^{-1}$, corresponding to the aliphatic $\mathrm{C}-\mathrm{H}$ stretching vibration, represent the existence of $-\mathrm{CH}_{2}-$ and $-\mathrm{CH}_{3}-$ groups in backbone structure of plasma polymer. The later peak $2960 \mathrm{~cm}^{-1}$ is more specific to the plasma polymerized sulfonated polystyrene than the conventional one, which specifies the cross linking structure in plasma polymerized membrane (Retzko et al 2001; Mahdjoub et al 2005). The peak at $754 \mathrm{~cm}^{-1}$ corresponding to the $\mathrm{C}-\mathrm{H}$ out of plane bending vibration of five $\mathrm{C}-\mathrm{H}$ bonds and the peek at 699 $\mathrm{cm}^{-1}$ representing the mono substituted benzene ring in the polymer backbone suggest the partial attachment of $-\mathrm{SO}_{3} \mathrm{H}$ groups into the aromatic ring of the polymer backbone ( $\mathrm{Su}$ et al 1994). The intense peak observed at $836 \mathrm{~cm}^{-1}$ indicates the substitution of proton by the sulfonate groups in the para position of the benzene ring (Fritzerald and Weiss 1986; Liu et al 2000). The absorption peaks present in the band $2000-1667 \mathrm{~cm}^{-1}$ also reveal both mono and 1, 4 disubstitution of benzene ring (Pavia et al 2001). All these observations made in the FTIR spectra suggest that plasma polymerized sulfonated polystyrene membranes have similar kind of chemical structure with conventional sulfonated polystyrene (Fritzerald and Weiss 1986; Zhong et al 2006).

\subsection{Deposition rate and surface morphology}

The plasma polymerized membranes developed in this experiment exhibit thickness in the range of 5 to $33 \mu \mathrm{m}$ depending on the deposition time and RF power density. In figure 3(a) 

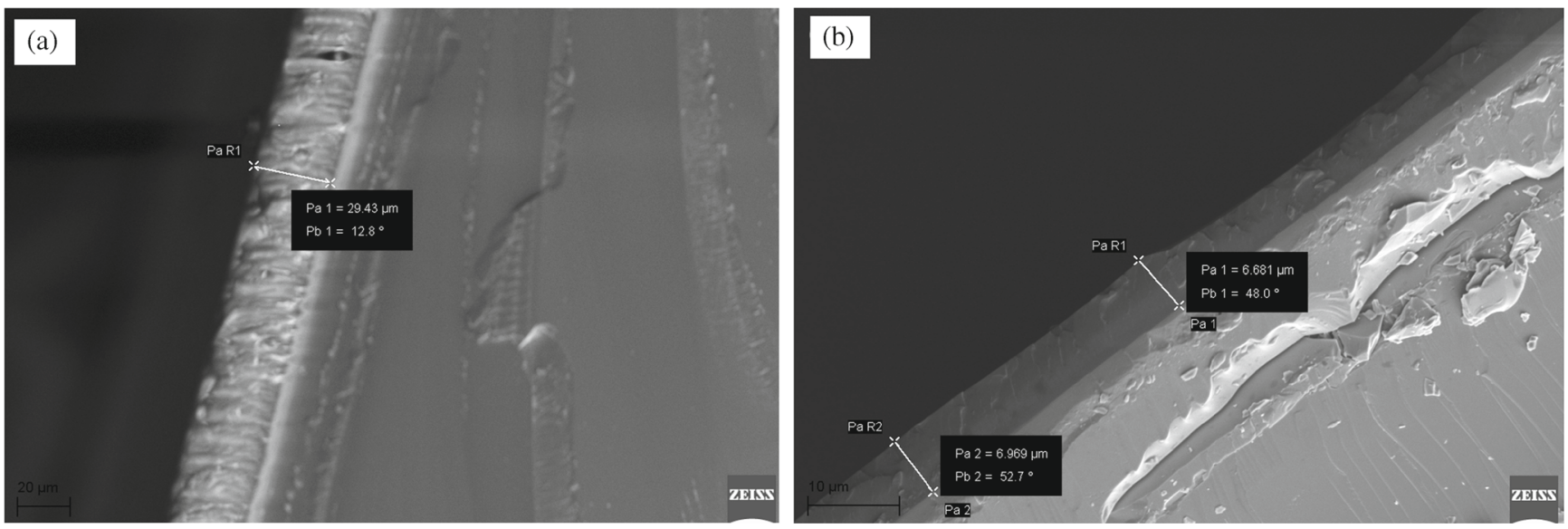

Figure 3. Cross sectional view of the plasma membranes: (a) PP-SPSM4 and (b) PP-SPSM1.

and (b), the cross sectional view of the membrane PP-SPS4 and PP-SPS1 are shown. It is seen that the deposition rate achieved in this experiment is too much high compared to the earlier works done by several groups (Mahdjoub et al 2005; Roualdes et al 2007; Ennajdaoui et al 2008, 2010; Jiang et al 2010a, b, 2011). This enhancement of deposition rate can be attributed to three distinct reasons.

Firstly, the deposition of the membrane is performed at higher flow rate of monomer. Secondly, the glow discharge is initiated only in the monomer vopour phase in absence of any inert or other gas which leads to formation of large number of styrene cations. Thirdly, the TMSA molecules are highly reactive to styrene molecules which may increase the possibility of conventional polymerization even in the vapour phase of monomer. Moreover, it is also seen that the polymerization with only styrene monomer under the same plasma operating conditions leads to tiny deposition rate in comparison to the co-polymerization of both monomers. So, it can be concluded that, in the presence of TMSA molecules in styrene plasma, the fragmentation rate of styrene molecules increases and produces more reactive chemical species to accelerate the rate of polymerization. The membranes are deposited at different power densities from 0.114 to 0.318 $\mathrm{Wcm}^{-2}$ for a fixed deposition time of $25 \mathrm{~min}$ and constant working pressure. The maximum thickness of $33 \mu \mathrm{m}$ is obtained at a deposition rate of nearly $33 \mathrm{nms}^{-1}$ at $0 \cdot 318$ $\mathrm{Wcm}^{-2}$ power density. Above this power density, the membrane becomes more brittle and poorly adhesive to the substrate. So, the membrane structure cannot be retained above $0.318 \mathrm{Wcm}^{-2}$ power density. This is mainly due to the formation of cross linked structure and bombardment of higher energetic ions on the surface of the membrane during deposition (Yang et al 2002). So, from the application point of view, the membrane developed in the power range of $0 \cdot 114-0.318 \mathrm{Wcm}^{-2}$ can be expected to be more efficient. Figure 4 shows the variation of the deposition rate with applied power density at a constant working pressure of styrene and TMSA monomers. It is observed that the deposition rate almost exponentially increases with power

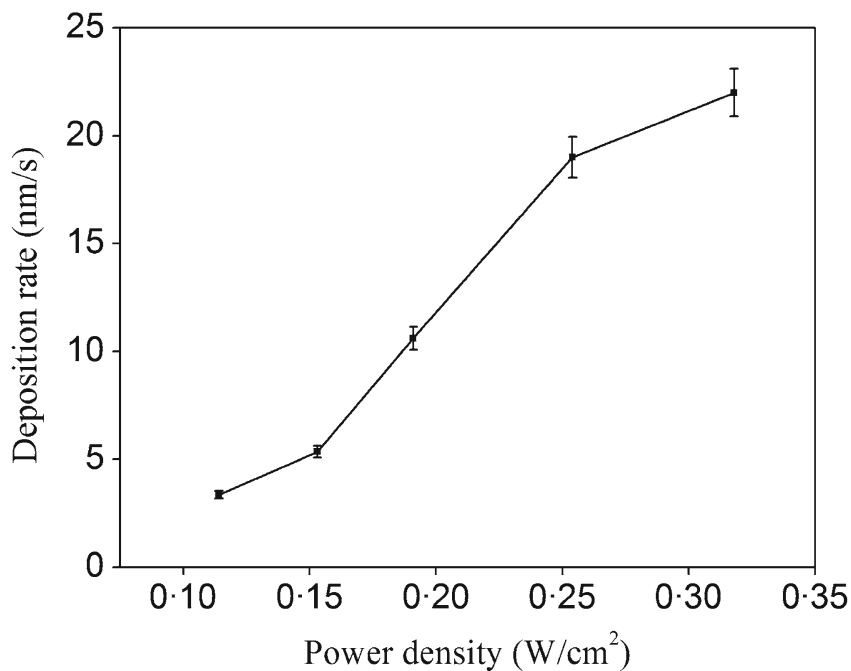

Figure 4. Variation of deposition rate with power density.

density in the range of $0.114-0.254 \mathrm{Wcm}^{-2}$ and then it becomes slower. This exponential rising in deposition rate is due to the simultaneous effect of power density and sulfonation of monomer molecules in plasma state. But the slowing down in deposition rate beyond $0.318 \mathrm{Wcm}^{-2}$ is due to higher fragmentation rate of monomer molecule as well as the energetic ion bombardment on the surface of the membrane during deposition. The surface morphology of the membrane is studied using SEM. Figure 5 shows SEM images of the membranes developed at different power density. From the SEM images, it is clear that the membranes PP-SPSM1 has relatively uniform and pinhole free surface, while the membrane PP-SPSM4 has a non uniform surface structure with some nano pores. This formation of non uniform structure is accounted for by the high energetic ion bombardment on the polymeric membrane. Figure 6 shows the energy dispersive X-ray spectra of different membranes. The elemental compositions of the membranes PP-SPSM1, PP-SPSM2, PP-SPSM3 and PP-SPSM4 

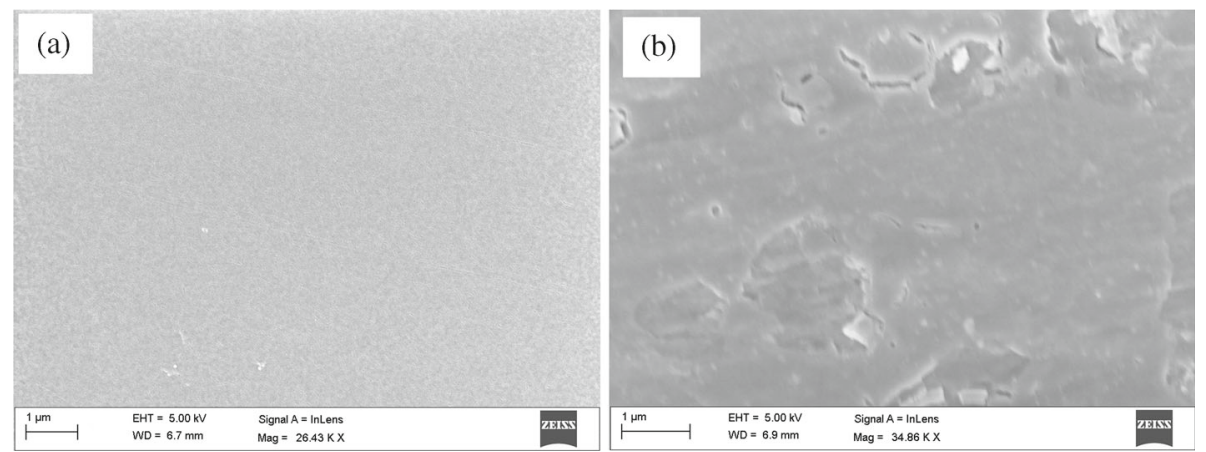

Figure 5. SEM images of plasma polymerized membranes: (a) PP-SPSM1 and (b) PPSPSM4.

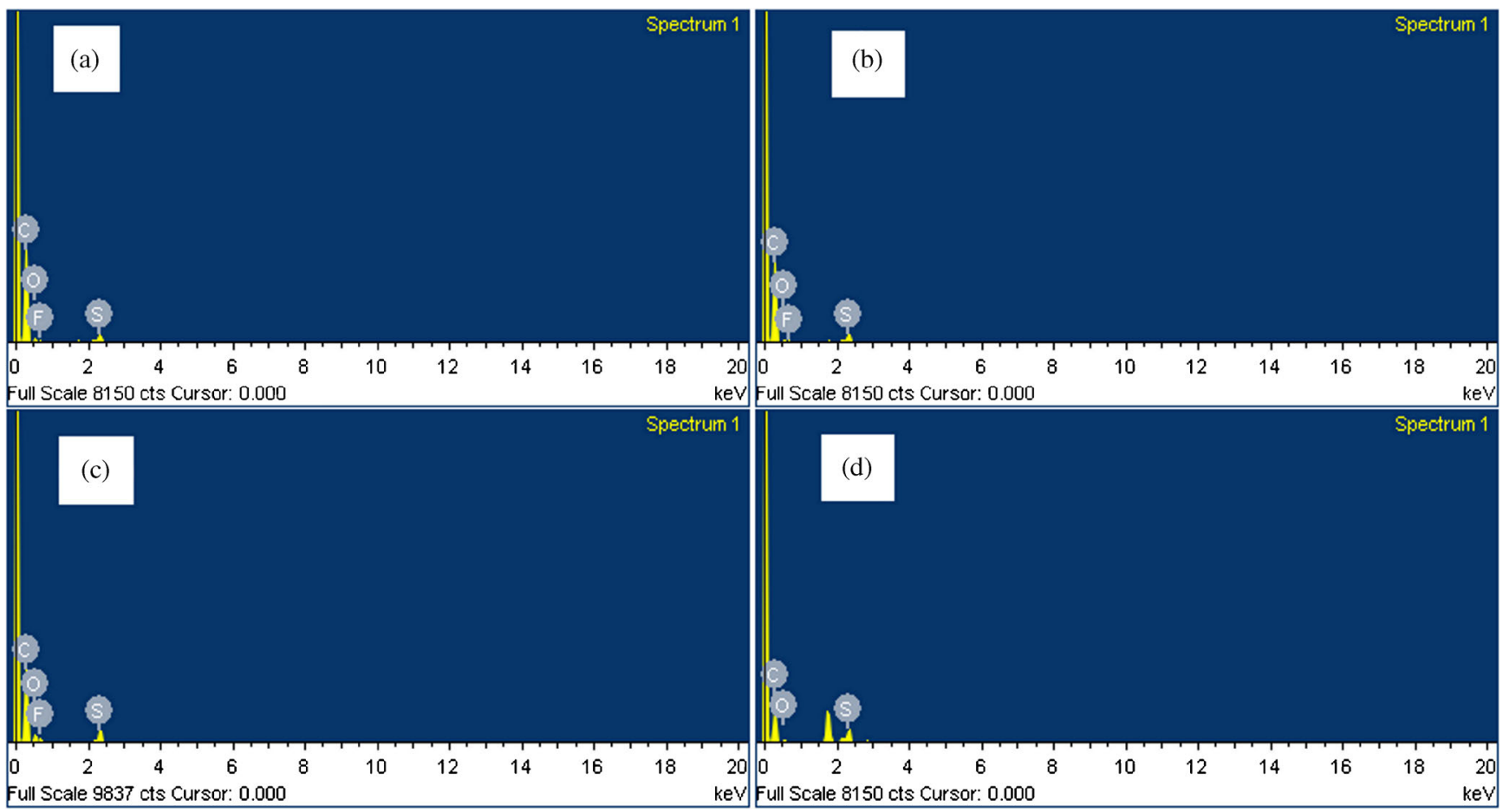

Figure 6. EDS spectra of plasma polymerized membranes: (a) PP-SPSM1, (b) PP-SPSM2, (c) PP-SPSM3 and (d) PP-SPSM4.

Table 3. Elemental composition of plasma polymerized membranes at different power densities.

\begin{tabular}{lccccc}
\hline Membrane & $\begin{array}{c}\text { Power density } \\
\left(\mathrm{Wcm}^{-2}\right)\end{array}$ & $\mathrm{C}(\%)$ & $\mathrm{O}(\%)$ & $\mathrm{F}(\%)$ & $\mathrm{S}(\%)$ \\
\hline PP-SPSM1 & 0.114 & 88.63 & 8.03 & 2.58 & 0.76 \\
PP-SPSM2 & 0.153 & 89.54 & 6.57 & 2.95 & 0.94 \\
PP-SPSM3 & 0.191 & 80.67 & 13.05 & 5.04 & 1.24 \\
PP-SPSM4 & 0.254 & 84.43 & 10.00 & 3.22 & 2.35 \\
\hline
\end{tabular}

are summarized in table 3 . It is observed that the percentage of sulfur content in plasma polymerized membrane (PP-SPSM1, PP-SPSM2, PP-SPSM3 and PP-SPSM4) increases with power density and it is found to be maximum for the membrane PP-SPSM4.

\subsection{Sulfonation rate}

The abundance of the $-\mathrm{SO}_{3} \mathrm{H}$ group in the plasma polymerized membrane is analyzed by calculating the sulfonation rate from the FTIR spectra of the membranes. In this study, we have used this technique to evaluate the sulfonation rate of plasma polymerization process. But, it is a qualitative estimation to richness of $-\mathrm{SO}_{3} \mathrm{H}$ groups attached into the polymer matrix as calculated from (1). This estimation cannot verify the exact chemical content of $-\mathrm{SO}_{3} \mathrm{H}$ groups in the plasma polymer (Ennajdaoui et al 2008, 2010). Figure 7 represents the variation of sulfonation rate evaluated from the FTIR spectra with power densities. From the figure, it is seen that sulfonation rate increases with the applied power density and maximum $66 \%$ is observed for the membrane PP-SPS4 synthesized at power densities 


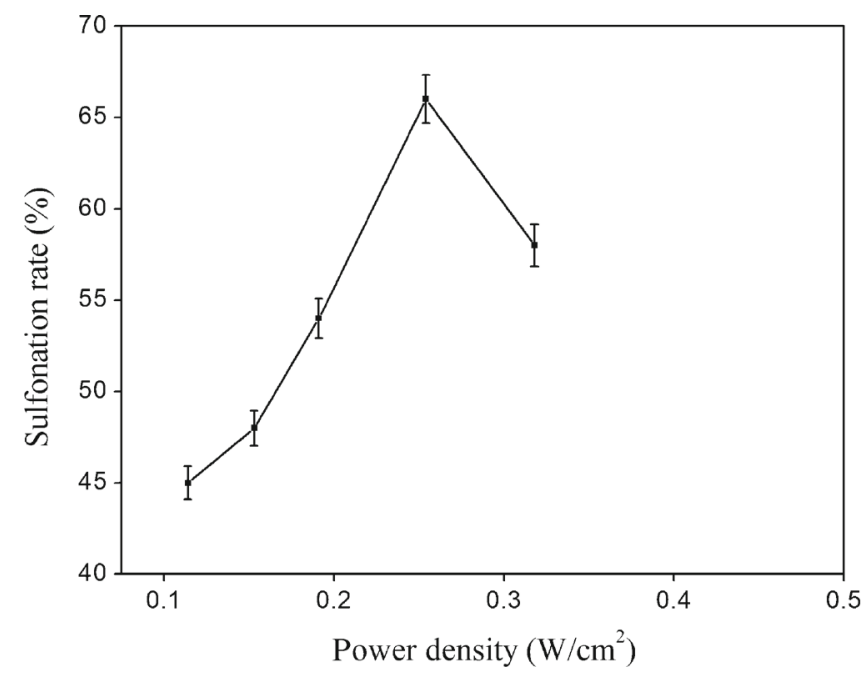

Figure 7. Variation of sulfonation rate with power density.

$0.254 \mathrm{Wcm}^{-2}$. Then, it starts to decrease with increasing power density which is clearly correlated to the variation of sulfur content from the EDS result as depicted in table 3. So, the amount of $-\mathrm{SO}_{3} \mathrm{H}$ groups associated in the plasma membrane PP-SPS4 is found to be maximum under the optimized plasma condition. This variation in percentage of the sulfonic acid groups observed in the plasma polymerized membranes deposited at different power densities can be interpreted as follows:

The plasma energy density of the monomer is calculated as $W /(F \cdot M)$, where $W$ is the plasma discharge power density, $F$ the monomer volume flow rate $(\mathrm{sccm})$ and $M$ the molecular weight of the monomer describing the behaviour of plasma polymerization (Yasuda and Hirotsu 1978; Yasuda and Dekker 2005). When the applied discharge power density is very low, the decomposition of monomer takes place only in the bond with lower bond energy and resulting the low molecular fragmentation rate and high recombination rate of free radicals and ions (Friedrich 2011). So, in case of styrene molecules, a small fraction of styrene cations are generated at low discharge power density. Similarly, a fewer amount of $-\mathrm{CF}_{3}^{+}$and $-\mathrm{SO}_{3}^{-}$ions on fragmentation of TMSA molecules at low discharge power density are generated which leads to poor sulfonation of styrene molecules. As the discharge power density increases, the fragmentation rate of both monomer molecules starts to increase. This results in the formation of a large number of styrene cations and anions in plasma phase leading to higher substitution rate of $-\mathrm{SO}_{3} \mathrm{H}$ groups in the para position of benzene ring of styrene molecules. With further increase in discharge power density, it is observed that the sulfonation rate falls abruptly. This is due to the effect of higher plasma energy supplied to the monomer. The probability of fragmentation of the monomer molecules in the bonds with higher bond energy increases at high discharge power density due to the higher collision rate and more ion energy. So, in the monomer deficient domain of plasma, TMSA molecules are destroyed more. Due to this, the degree of substitution of $-\mathrm{SO}_{3} \mathrm{H}$ groups in the para position of aromatic ring is reduced and hence sulfonation rate of the membranes is decreased beyond $0.254 \mathrm{Wcm}^{-2}$ power density. So, it can be concluded that the discharge power density is a key parameter for the sulfonation of styrene monomer in the plasma phase.

\subsection{Ion exchange capacity and proton conductivity}

The ion exchange capacity of a polymer electrolyte indicates the amount of sulfonate groups consumed in the polymer structure. The measured IEC values of the prepared membranes are shown in table 4. It is observed that IEC value is maximum for the membrane PP-SPSM4 synthesized at $0.254 \mathrm{Wcm}^{-2}$ which is correlated with the sulfonation rate of same membrane as presented in figure 7. The proton conductivity is one of the key parameters of PEM which determines the efficiency of a fuel cell. It is complicated to establish a relation between the proton conductivity and structural properties of the membranes. Still, it is accepted that higher proton exchange groups consumed in the polymer and higher water uptake facilitate the migration of proton across the membrane and hence it helps to enhance the proton conductivity. The Nyquist plots of the impedance data recorded for the membranes are shown in figure 8 from which membrane ion resistance was calculated using (4). The proton conductivity of the synthesized plasma membranes is studied with membrane depositing power density. It is found that all membranes have shown better proton conductivity than the plasma polymerized membrane developed earlier and commercially available Nafion membrane (Jiang et al 2011). Figure 9 represents the variation of proton conductivity of the membrane with depositing power density. From the figure, it is observed that the proton conductivity increases with depositing power density and it is maximized up to $0.602 \mathrm{Scm}^{-1}$ for the membrane PP-SPS4 deposited at $0.254 \mathrm{Wcm}^{-2}$ power density. Beyond this, the conductivity again decreases with increasing power density. So, this variation of conductivity with power density can be interpreted from the sulfonation level which is approximated from the IEC value, water uptake and nano porous structure of the membrane (Jiang et al 2011). The proton mobility across the membrane is highly dependent on the hydrophilic sulfonate groups present in the polymer matrices. This active proton exchange group facilitates the water uptake capacity into the polymer due to their hydrophilic nature. In case of plasma polymerized materials, the water uptake and sulfonation level depend on depositing conditions of membrane. The various properties of the membrane developed at different power density are shown in table 4 . From table 4 , it is seen that the plasma polymerized membranes deposited in all plasma conditions exhibit more water uptake capacity than nafion membrane and the chemically prepared membrane (Jiang et al 2011). This enhancement of the water uptake may be due to nano porous structure retained in the plasma polymerized membrane. It is observed that the membranes 
Table 4. Properties of the plasma polymerized membrane deposited at different power densities.

\begin{tabular}{|c|c|c|c|c|c|c|}
\hline Membrane & $\begin{array}{l}\text { Power density } \\
\quad\left(\mathrm{Wcm}^{-2}\right)\end{array}$ & $\begin{array}{l}\text { Deposition rate } \\
\quad\left(\mathrm{nms}^{-1}\right)\end{array}$ & $\begin{array}{l}\text { Sulfonation } \\
\text { rate }(\%)\end{array}$ & $\begin{array}{c}\text { Ion exchange } \\
\text { capacity }\left(\text { meqg }^{-1}\right)\end{array}$ & $\begin{array}{l}\text { Proton conductivity } \\
\qquad\left(\mathrm{Scm}^{-1}\right)\end{array}$ & Water uptake $(\%)$ \\
\hline PP-SPSM1 & $0 \cdot 114$ & $3 \cdot 35$ & 45 & 0.41 & $0 \cdot 159$ & 140 \\
\hline PP-SPSM2 & $0 \cdot 153$ & $5 \cdot 34$ & 48 & $0 \cdot 72$ & $0 \cdot 220$ & 120 \\
\hline PP-SPSM3 & $0 \cdot 191$ & $10 \cdot 6$ & 54 & 0.97 & 0.402 & 100 \\
\hline PP-SPSM4 & $0 \cdot 254$ & 19 & 66 & 1.69 & 0.602 & 90 \\
\hline PP-SPSM5 & $0 \cdot 318$ & 22 & 58 & $0 \cdot 89$ & $0 \cdot 311$ & 80 \\
\hline
\end{tabular}

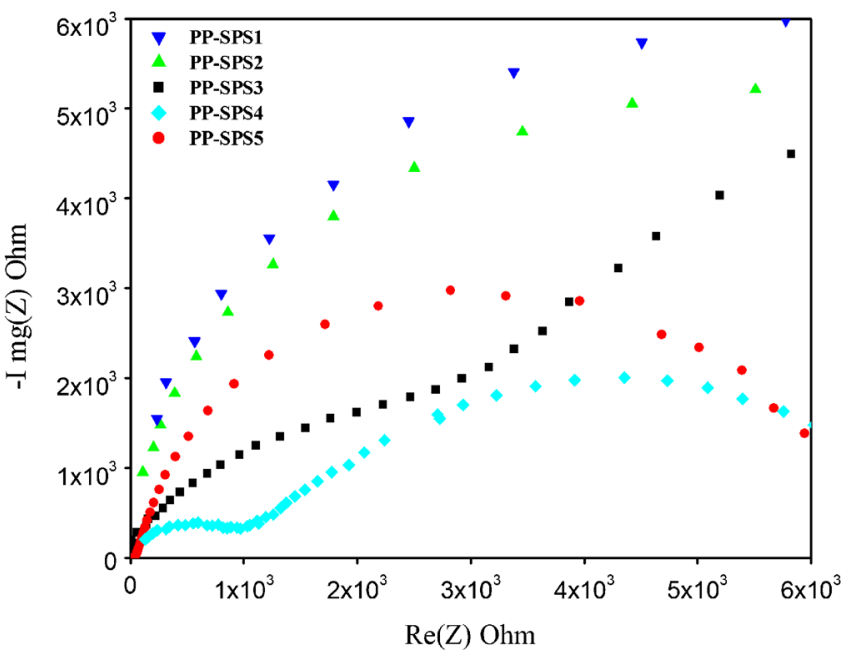

Figure 8. Nyquist plots of the plasma polymerized membranes deposited at different power densities.

deposited in low power density show higher water uptake and then it starts to decrease with increasing power density. This may be convenient for plasma polymerized membrane because the high power density yielding more self bias during polymerization aids the formation of compact structure with cross linking network. This finding further can be confirmed by gel permeation chromatography (GPC) results, which shows two types of molecular weight distribution in polymer. A typical molecular weight distribution curve for the membranes PP-SPSM3 is shown in figure 10. The weight average molecular weight and number average molecular weight of PP-SPSM1, PP-SPSM2, PP-SPSM3 and PPSPSM4 membranes deposited at different power density are represented in table 5. This clearly indicates a greater presence of highly branched and cross linking chemical structure in PP-SPSM4 membrane than in PP-SPSM1, PP-SPSM2 and PP-SPSM3 membranes. So, the plasma polymer deposited at higher power density possesses higher material density and, thereby, decreases the water uptake capacity for such kind of membrane.

The ionic conduction in a solid polymer electrolyte is a thermally activated process. So, the study of the temperature dependence of conductuvity gives the detailed information about the ionic resistance of the membrane with temperature

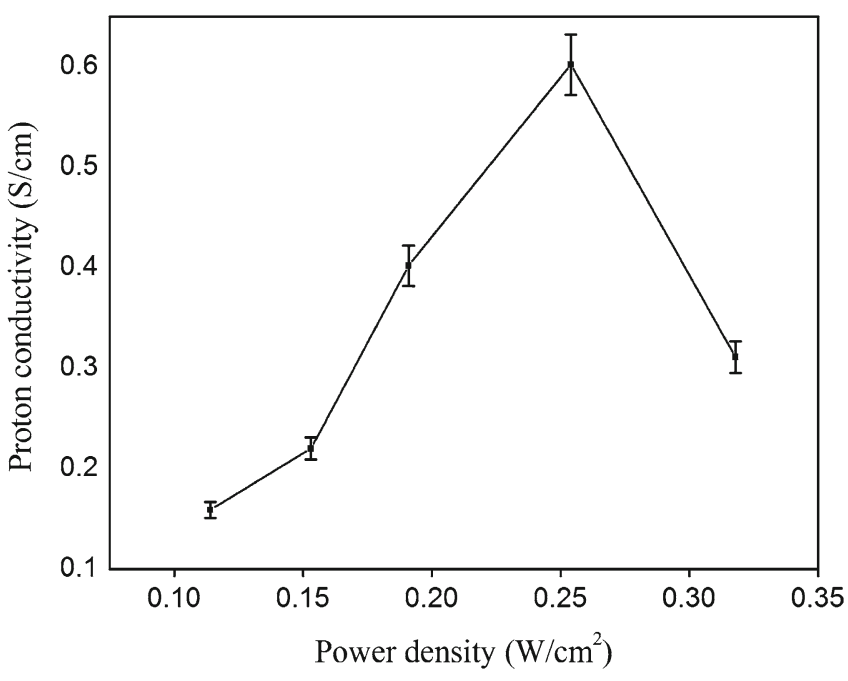

Figure 9. Variation of proton conductivity with power density.

and it follows a simple Arrhenius-type law as a function of temperature. Figure 11 shows the temperature dependence of the proton conductivity of the plasma polymerized PPSPSM1 and PP-SPSM4 membranes, from which the activation energy $E_{\mathrm{a}}\left(\mathrm{kJ} \mathrm{mole}^{-1}\right)$ for proton conduction can be calculated by the linear least square fit of the temperature dependent conductivity plot using equation

$$
\ln \sigma=\ln \sigma^{\mathrm{o}}-\frac{E_{\mathrm{a}}}{R T},
$$

where $\sigma$ is the proton conductivity $\left(\mathrm{mScm}^{-1}\right), \sigma^{\circ}$ the pre exponential $\left(\mathrm{mScm}^{-1}\right)$ and, $R$ and $T$ are the pure gas constant and temperature $(\mathrm{K})$ respectively.

The activation energy of proton conduction found for plasma polymerized PP-SPSM1 and PP-SPSM4 membranes are 16.8 and $20.5 \mathrm{~kJ} \mathrm{~mole}^{-1}$ respectively which clearly indicates the gain of activation energy with depositing power density. The membrane with more cross linking structure needs more activation energy to transport the proton from one free site to another. So, the membrane PP-SPSM4 having more cross linking structure possesses higher activation energy for proton conduction than the membrane PP-SPSM1 deposited at low power density. 


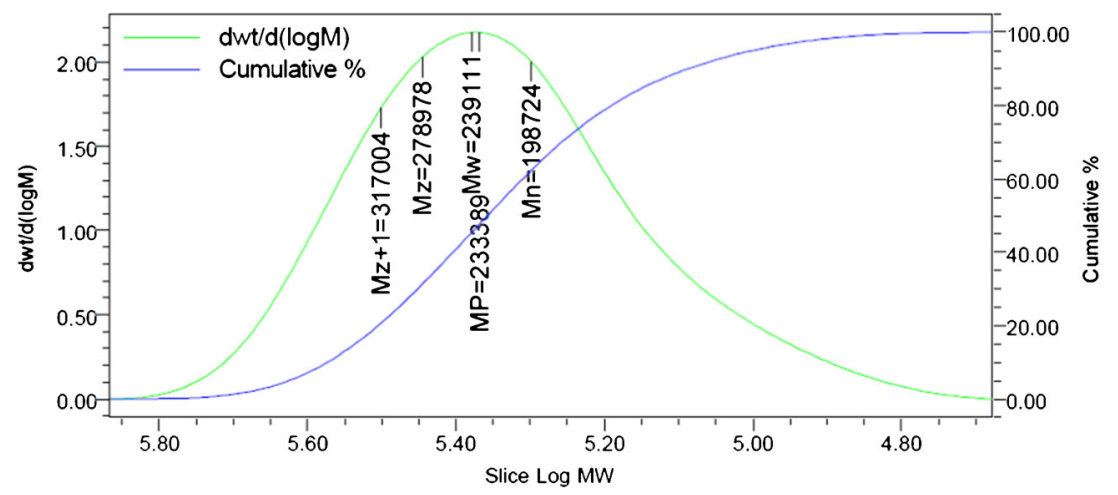

Figure 10. Molecular weight distribution curve of the membrane PP-SPSM3 deposited at $0 \cdot 191 \mathrm{Wcm}^{-2}$ power density.

Table 5. GPC data of sulfonated polystyrene membrane deposited at different power densities.

\begin{tabular}{lccc}
\hline Membrane & $M_{\mathrm{n}}$ & $M_{\mathrm{w}}$ & Polydispersity \\
\hline PP-SPSM1 & 4448 & 4449 & $1 \cdot 00$ \\
PP-SPSM2 & 6472 & 6670 & 1.03 \\
PP-SPSM3 & 198724 & 238724 & 1.20 \\
PP-SPSM4 & 233655 & 539763 & $2 \cdot 31$ \\
\hline
\end{tabular}

$M_{\mathrm{n}}$ : Number average molecular weight. $M_{\mathrm{w}}$ : Weight average molecular weight.

\subsection{Thermal stability}

In order to investigate the thermal stability of plasma polymerized membrane, thermogravimetric analysis (TGA) was performed. The TGA curves of the membranes are shown in figure 12. It is observed that the sulfonated polystyrene membrane shows maximum thermal stability up to $140^{\circ} \mathrm{C}$. Generally, the plasma polymerized polystyrene film exhibits higher thermal stability up to $200{ }^{\circ} \mathrm{C}$ (Choudhury et al 2011). So, it can be concluded that the thermal stability of sulfonated polystyrene is highly influenced by the sulfonic acid groups incorporated into the aromatic polymer backbone. From figure 12, it is clear that the membrane PP-SPSM1 exhibits higher thermal stability up to the temperature $140{ }^{\circ} \mathrm{C}$ and then it starts to decrease down to $129^{\circ} \mathrm{C}$ for the membrane PP-SPSM4 deposited at $0.254 \mathrm{Wcm}^{-2}$ power density. This variation of thermal stability of the synthesized membranes can be attributed to the impact of $-\mathrm{SO}_{3} \mathrm{H}$ groups into plasma polymer. It is also noticeable that the polymer synthesized at higher power density exhibits higher thermal stability. But, in this study, it is almost reversed due to enormous impact of sulfonation.

To have a better understanding of the thermal decomposition of different constituents of the membrane in detail, the TGA/DTA curves of the membranes PP-SPSM1 and PPSPSM4 are represented in figure 13(a) and (b) respectively. From the TGA/DTA profiles, three significant decomposition

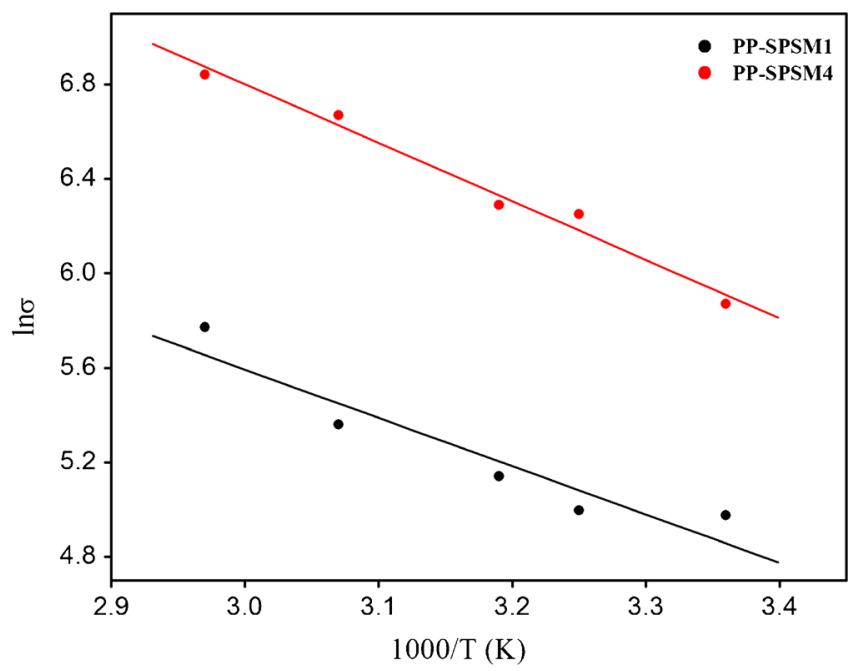

Figure 11. Arrhenius plot showing temperature dependence of membrane proton conductivity.

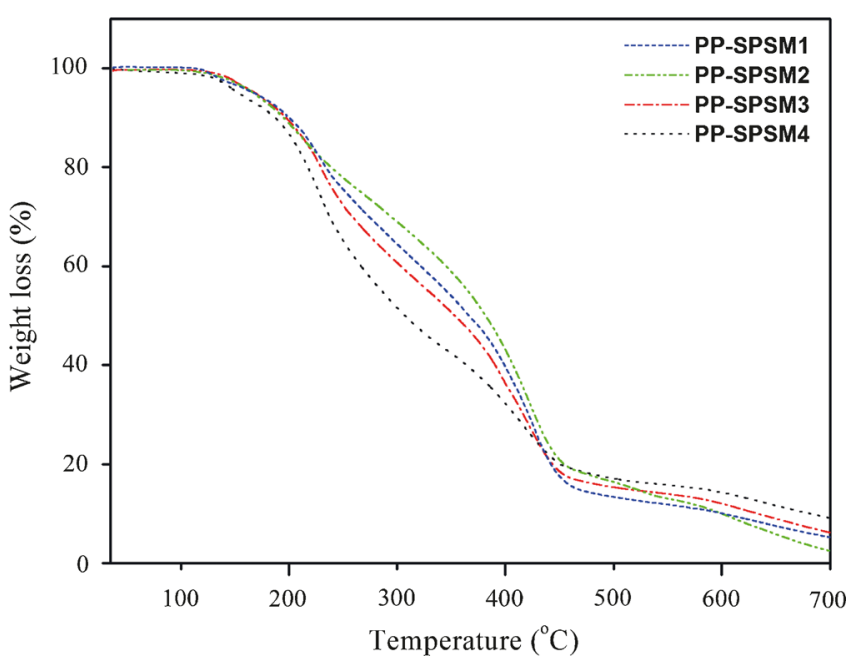

Figure 12. TGA curves of the deposited membranes at different power densities. 

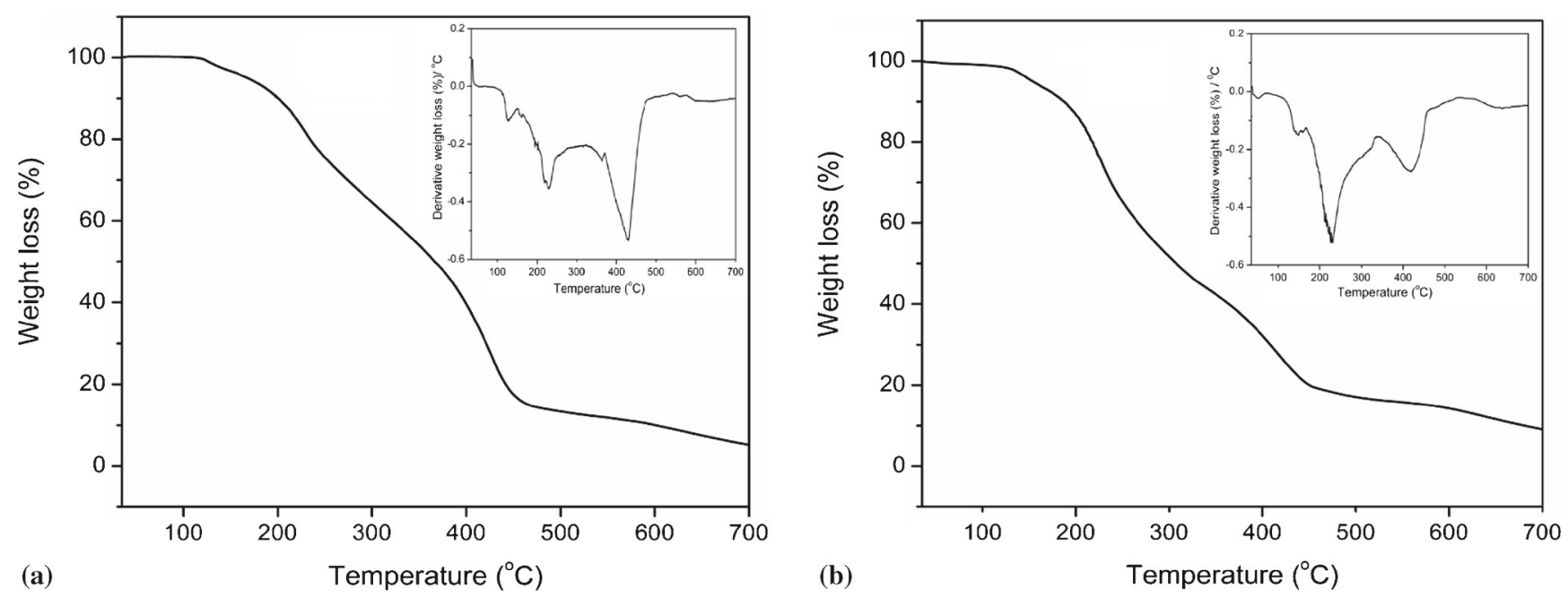

Figure 13. (a) TGA and DTA (inset) curve of PP-SPSM1 membrane and (b) TGA and DTA (inset) curve of PP-SPSM4 membrane.

zones are observed at around 148,230 and $420{ }^{\circ} \mathrm{C}$ for the membrane PP-SPSM4 synthesized at $0.254 \mathrm{Wcm}^{-2}$ power density and at around 150,245 and $440{ }^{\circ} \mathrm{C}$ for the membrane PP-SPSM1 synthesized at $0 \cdot 114 \mathrm{Wcm}^{-2}$ power density. The other three zones are at 148,230 and $425^{\circ} \mathrm{C}$ for the membrane PP-SPSM3 synthesized at $0.191 \mathrm{Wcm}^{-2}$ power density and 150,247 and $447^{\circ} \mathrm{C}$ for the membrane PP-SPSM2 synthesized at $0.153 \mathrm{Wcm}^{-2}$ power density. From the above observation on TGA curves, it is seen that the first step degradation occurs around $150{ }^{\circ} \mathrm{C}$ for each membrane. This weight loss of nearly $5 \%$ may be due to removal of water molecules. The second step degradation of membranes is varied with depositing power density and this degradation is mainly due to the decomposition of sulfonate groups and some parts of aliphatic groups from the sulfonated polystyrene (Choi and Jo 2009). It is at around $230^{\circ} \mathrm{C}$ for the membrane PP-SPSM4 in which the weight loss is found to be maximum at nearly $26 \%$. Whereas the minimum $18 \%$ weight loss is observed at around $247^{\circ} \mathrm{C}$ for membrane PP-SPSM 2 which is less than that of membrane PP-SPSM1. This may be due to presence of some cross-linked structure in the membrane PP-SPSM2 than in the membrane PP-SPSM1 and, therefore, it is found to be more stable in this temperature region. This degrading temperature zone is more significant because the polymer decomposition takes place in the sulfonic acid groups which is clearly reflected in the sulfonation rates evaluated from the FTIR spectra of each membrane. The third decomposition zone depicted from the TGA/DTA profile is at around $420{ }^{\circ} \mathrm{C}$ for the membrane PP-SPSM4. It is prominent that this temperature zone is also varied with depositing power density. As the depositing power density decreases, this temperature zone also rises and it is around $447{ }^{\circ} \mathrm{C}$ for the membrane PP-SPSM2. This decomposition can be attributed to the degradation of polymer backbone structure, mainly the decomposition of aromatic parts from the polymer (Choi and Jo 2009; Chen and Hong 2004). Moreover, the minimum $50 \%$ weight loss is observed in this zone for the membrane PP-SPSM4 and maximum $60 \%$ for the membrane PP-SPSM1. This is due to the influence of applied power density and the self bias developed at the substrate during polymerization which leads to formation of higher cross linking structure at synthesizing power density of $0.254 \mathrm{Wcm}^{-2}$. Hence, it reduces the weight loss in this temperature zone for the same membrane.

\section{Conclusions}

Polystyrene based proton exchange membranes were synthesized under different plasma operating conditions in continuous glow discharge with capacitively coupled electrode system. All the membranes were prepared at constant working pressure of 0.160 mbar and constant deposition time of $25 \mathrm{~min}$. In this study, we are able to deposit thick membranes with higher deposition rate. The film structure can be sustainable up to the synthesizing power density of $0 \cdot 318 \mathrm{Wcm}^{-2}$ and, beyond this power density, the membrane becomes brittle. So the membranes synthesized below the power density of $0.318 \mathrm{Wcm}^{-2}$ can be expected to be more suitable in a fuel cell for low temperature operation. The physical properties of the membrane developed at different plasma conditions were investigated in a small range of power density from 0.114 to $0.318 \mathrm{Wcm}^{-2}$. A well correlation among the proton conductivity, sulfonation rate and IEC has been observed which is convenient for all polymer electrolyte material. In this study, it is also seen that the proton mobility and water absorption capacity of plasma polymer not only depend on sulfonation level but also on internal structure of the membrane. In principle, water uptake capacity of a membrane can be controlled by the sulfonation level of the polymer. It is also found that the plasma polymerized proton exchange membrane can absorb excess amount of water due to which the water uptake capacity of the membrane becomes higher(Mahdjoub et al 2005; Jiang et al 2011). 
The functional properties of a membrane are highly dependent on the structure of polymer matrixes determined by the applied power density during polymerization. Therefore, it can be emphasized that RF power density carries a great role in formation of polymer membrane structure and, consequently, in their properties. So, this investigation obviously reflects the effect of plasma energy on the structural and physical properties of the plasma polymerized sulfonated polystyrene membrane.

\section{Acknowledgement}

The authors are grateful to the Ministry of New and Renewable Energy (MNRE), Govt. of India, for sponsoring the project (Grant no.: 102/64/2009-NT).

\section{References}

Bae I S, Cho S H, Lee S B, Kim Y and Boo J H 2005 Surf. Coat. Technol. 193142

Baradie B, Poinsignon C, Sanchez J Y, Piffard Y, Vitter G, Bestaoui N, Foscallo D, Denoyell A, Delabouglise D and Vaujany M 1998 J. Power Sources 748

Blanchard R M and Nuzzo R G 2000 J. Polym. Sci. Part B: Polym. Phys. 381512

Brumlik C J, Parthasarathy A, Chen W J and Martin C R 1994 J. Electrochem. Soc. 1412273

Chen N and Hong L 2004 Polymer 452403

Choi W H and Jo W H 2009 J. Power Sources 188127

Choudhury A J, Chutia J, Braves S A, Kakati H, Pal A R, Jagannath, Mithal N, Kishore R, Pandey M and Patil D S 2011 Prog. Org. Coat. 7075

Ennajdaoui A, Larrieu J, Roualdes S and Durand J 2008 Eur. Phys. J. Appl. Phys. 429

Ennajdaoui A, Roualdes S, Brault P and Durand J 2010 J. Power Sources 195232

Friedrich J 2011 Plasma Process. Polym. 8783

Fritzerald J J and Weiss R A 1986 ACS Symposium Series 30235

Gruger A, Regis A, Schmatko T and Colomban P 2001 Vib. Spectrosc. 26215

Inagaki N, Tasaka S and Horikawa Y 1989 J. Polym. Sci. Polym. Ed. 273495
Jiang Z Q, Jiang Z J and Meng Y 2011 J. Membr. Sci. 372303

Jiang Z Q, Jiang Z J, Yu X Y and Meng Y D 2010a Plasma Process. Polym. 7382

Jiang Z Q, Jiang Z J, Yu X Y, Meng Y D and Li J G 2010b Surf. Coat. Technol. $205 \mathrm{~S} 231$

Liu H M, Liu J C, Zhu F M and Alin S 2000 Polym. Int. 50421

Mahdjoub H, Roualdes S, Sistat P, Pradeilles N, Durand J and Pourcelly G 2005 Fuel Cells 5277

Morse J D 2007 Int. J. Energy Res. 31576

Pavia D L, Lampman G and Kriz G 2001 Introduction to Spectroscopy, 3rd edn (Philadelphia, USA: Harcourt College Publisher)

Peighambardoust S J, Rowshanzamir S and Amjadi M 2010 Int. J. Hydrogen. Eng. 359349

Poll H U, Arzt M and Wicklender K H 1976 Eur. Polym. J. 12505

Psark D E, Kim T, Kwon S, Kim C K and Yoon E 2007 Sens. Actuators A 13558

Rieke P C and Vanderborgh N E 1987 J. Membr. Sci. 32313

Roualdes S, Schieda M, Durivault L, Guesmi I, Gerardin E and Durand J 2007 Chem. Vap. Deposition 13361

Retzko I, Friedrich J F, Lippitz A and Unger W E S 2001 J. Electron Spectros. Relat. Phenom. 121111

Su Z, Li X and Hsu S L 1994 Macromolecules 27287

Wan N, Wang C and Mao Z 2007 Electrochem. Commun. 9511

Wirguin C H 1979 Polymer 20371

Xing P, Robertson G P, Guiver M D, Mikhailenko S D and Kailiaguine S 2004 Macromolecules 377960

Yang J C, Jablonsky M J and Mays J W 2002 Polymer 435125

Yasuda H 1981 J. Polym. Sci. Macromol. Rev. 16199

Yasuda H and Dekker M (eds) 2005 Luminous chemical vapor deposition and interface engineering New York, USA

Yasuda H and Hirotsu T 1978 J. Polym. Sci. Polym. Chem. Ed. 16 743

Yasuda H, Bumgarner M O, March H C and Morosoff N 1976 J. Polym. Sci. Chem. Ed. 14195

Yasuda K, Uchimoto Y, Ogumi Z and Takehara Z 1994a Ber. Bunsenges. Phys. Chem. 98631

Yasuda K, Uchimoto Y, Ogumi Z and Takehara Z 1994b J. Electrochem. Soc 1412350

Yeom J, Mozsgai G Z, Flachsbart B R, Choban E R, Asthana A, Shannon M A and Kenis P J A 2005 Sens. Actuators B 107882

Zhong S, Fu T, Dou Z, Zhao C and Na H 2006 J. Power Sources 16251 